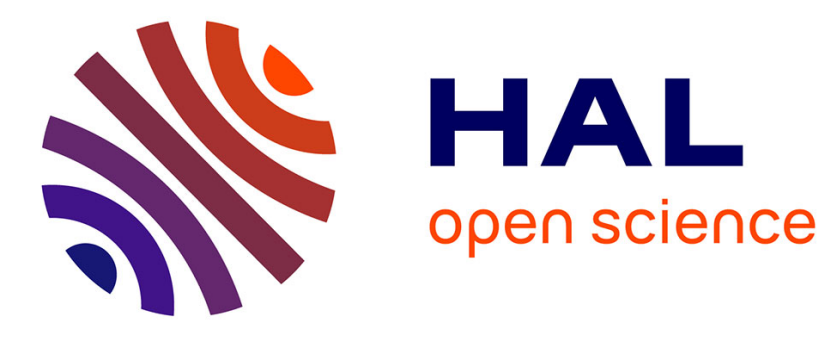

\title{
Environmental Management Practices for the Textile Sector
}

\author{
Barbara Resta, Stefano Dotti, Albachiara Boffelli, Paolo Gaiardelli
}

\section{To cite this version:}

Barbara Resta, Stefano Dotti, Albachiara Boffelli, Paolo Gaiardelli. Environmental Management Practices for the Textile Sector. IFIP International Conference on Advances in Production Management Systems (APMS), Sep 2015, Tokyo, Japan. pp.625-631, 10.1007/978-3-319-22756-6_76 . hal-01417626

\section{HAL Id: hal-01417626 \\ https://hal.science/hal-01417626}

Submitted on 15 Dec 2016

HAL is a multi-disciplinary open access archive for the deposit and dissemination of scientific research documents, whether they are published or not. The documents may come from teaching and research institutions in France or abroad, or from public or private research centers.
L'archive ouverte pluridisciplinaire HAL, est destinée au dépôt et à la diffusion de documents scientifiques de niveau recherche, publiés ou non, émanant des établissements d'enseignement et de recherche français ou étrangers, des laboratoires publics ou privés. 


\title{
Environmental Management Practices for the Textile Sector
}

\author{
Barbara Resta, Stefano Dotti, Albachiara Boffelli, Paolo Gaiardelli \\ CELS - Research Group on Industrial Engineering, Logistics and Service Operations, \\ Department of Management, Information and Production Engineering, viale Marconi 5, 24044, \\ Dalmine (BG), Italy \\ \{barbara. rest a; st ef ano. dot ti ; al bachi ar a. bof f el li ; \\ paol o.gai ardel I i \}@ini bg. i t
}

\begin{abstract}
Environmental sustainability is gaining more and more relevance for textile companies. However, there are often problems with application, even in the most committed companies. In this paper, an empirical typology of Italian textile firms that discern the patterns of practices used in response to environmental issues and concerns that affect such industry is proposed. The resulting typology is composed by three types: Best practice, Good practice and Bad practice. Each type is then characterised in terms of firm's characteristics and perceived environmental competitiveness benefits. The discussion of some open issues deriving from the empirical analysis precedes the final conclusion.
\end{abstract}

Keywords. Environmental sustainability; environmental management practices; environmental competitiveness; textile sector.

\section{Introduction}

Over the past decades, many companies have started to included environmental considerations into their business activities in order to decrease or eliminate the impact of these activities on the natural environment [1]. The concept of corporate environmental management [2] was introduced at the beginning of the '90s to help managers handle this new situation, translating the concept of environmental sustainability into a managerial tool for company managers. Although previous studies have made significant contributions to the literature on environmental issues, much still remains to be learnt about how companies include this challenge and opportunity into new strategic and operational options [3]. Moreover, most of the existing studies are too general and theoretical, and the assumption that all the business are facing a similar environmental problem is rarely appropriate [4]. The specific industrial context tends to shape the strategies and management sys- 
tems that exist at the firm-level due to its unique regulations and the influence of its stakeholders [5]. In particular, the textile sector is one of the industries mostly affected by environmental issues and concerns: it is one of the world's largest industries, while also one of the most polluting [6]. Thus, sustainability principles, strategies and tools have then become essential for textile companies to stay competitive in the market [7].

In such a context, this article aims at developing an empirical typology of the Italian textile companies by statistically identifying consistent and recurring patterns (types) of environmental management practices.

The paper is organised as follows. The next section outlines the theoretical background of the study. In Section 3, the research methodology will be described by presenting the research model and the empirical study carried out in the Italian textile sector. In Section 4, the research findings are discussed and implications of the findings are presented. Finally, the last section (Section 5) closes the paper with the most relevant conclusions and future research directions.

\section{Theoretical background}

Environmental Management Practices (EMPs) refer to all the measures and activities aimed at reducing the environmental impact caused by a company's business. Despite many management practices are often lumped together as simply "environmental", it is important that practices are effectively distinguished from one another. Sroufe et al. [8], classified the practices on the basis of their scope, that might be operational, tactical or strategic, thus pertaining to different foci, representing different resource commitments and targeting a wide range of goals and objectives. The authors continued underlying that for a firm to be committed to environmental management, it must be aware of holistic environmental concerns, coordinating and integrating activities across operational, tactical and strategic levels. Another standpoint, relying on the resource-based view, was embraced by Lucas [9], where the EMPs were categorised along two dimensions: the different capital investment types and the stages at which they affect the production process, while Colicchia et al. [10] distinguished between intra-organisational and inter-organisational environmental practices. The former refers to practices related to company "in-house" processes, while the latter to initiatives that imply collaboration and trust among multiple supply chain 
members. In general, it can be affirmed that researchers have surveyed firms' adoption of EMPs, identifying their adoption either within a specific sector, or across industries, considering specific firm size, or adopting a longitudinal perspective. EMPs have also been studied in relation to environmental and economic performance and influencing factors. However, due to the lack of an exhaustive framework for EMPs, each paper relies on a different set of practices drawn by the authors from the literature on environmental issues. To fill this gap, Resta et al. [11] proposed a comprehensive classification framework for environmental sustainability practices by combining a systematic literature review with a web content analysis of ten European sustainability leaders, selected according to the Dow Jones Sustainability Europe Index. The resulting theoretical framework, containing 57 practices divided into 6 areas, represents a reference framework for EMP and is potentially applicable to every sector. In particular, it was used to survey the Italian Textile, Clothing and Leather (TCL) industry by content-analysing the corporate websites. As one of first research devoted to understanding the practices for environmental sustainability in the Italian TCL supply chain, although it is exploratory in nature, some interesting findings were hypothesised from this study. However, the direct collection of empirical data is necessary to validate the current research findings and to further describe the distribution of the environmental sustainability phenomenon in the considered population and to analyse how such phenomenon contribute to corporate competitiveness. In particular, two main research question arise: "Are there consistent and recurring patterns of environmental practices which can be viewed as an empirical typology?"; "What are the competitiveness benefits related to each type?". Therefore this study attempts to: i) discern empirically the patterns (or types) of practices used by Italian textile companies in response to environmental issues and concerns that affect such industry, ii) analyse which are the main firm characteristics (in terms of size, production segment, vertical integration, and environmental strategy) of each individuated type, and iii) identify the environmental competitiveness benefits that are related to each type.

\section{Research Methodology}

A descriptive survey research has been conducted to shed light on the above-mentioned research questions. 


\subsection{The conceptual model}

Measures for environmental management practices were drawn from [11] and were finalized during a pilot study. Several associations, both at national and European level, were also consulted. In total, 33 measures were considered, categorised into 13 categories (Product, Raw materials, Packaging, Supply chain, Transportation, Environmental Management System (EMS), Energy management, Water management, Waste management, Air emission management, Materials, Culture, Governance). For each practice, managers were asked to indicate its use (dummy variable: $0=$ "not used"; $1=$ "used") in the company. For each category, the intensity of EMPs was computed with an index constructed as a single scale of continual variation $[0, ., 1]$ (where $0=$ worst EMP profile; 1= best EMP profile), which allowed the practice aggregation process at category level.

Measurement of competitiveness is complex because no commonly accepted definition of this concept exists and, consequently, it should include as many business performance dimensions as possible to provide a holistic view of environmental management's effects on firms' competitiveness [12]. Therefore, a firm's self-assessment approach based on a number of items has been employed. Environmental competitiveness self-assessment was thus measured by asking managers to select the perceived competitive benefits from a list. Then, the items were aggregated into 3 categories (Revenue growth, Cost savings and Compliance and risk), computed with an index constructed as a single scale of continual variation $[0, ., 1]$ (where $0=$ no environmental competitiveness; $1=$ high environmental competitiveness).

\subsection{Data Collection and Analysis}

The primary data for this study was collected through a web survey in June-July 2014. The questionnaire was administered to the total population of Italian textile companies included in the AIDA database (NACE code: 13) having an email contact publically available, totalling 1509. In total, 303 usable responses returned to the authors, corresponding to a response rate of $20 \%$. In order to identify consistent and recurring patterns of environmental practices, agglomerative hierarchical cluster analysis was employed to group the textile companies into homogeneous categories. The software used to perform the cluster 
analysis statistical calculation was the IBM® SPSS ${ }^{\circledR}$ Statistics Version 20 .

\section{$4 \quad$ Results and Discussion}

\subsection{Cluster Analysis Results}

Initially, the number of clusters had to be chosen. The hierarchical agglomerative clustering method to form groups was employed. During the course of agglomeration, squared Euclidean distance was used to calculate the distance between each pair of companies. As a result, three types (clusters) were formed. The profile of the variables for the solution with three clusters is presented in Table 1.

Table 1. Cluster analysis of environmental practice implementation

\begin{tabular}{|l|c|c|c|c|}
\hline \multicolumn{1}{|c|}{ Cluster } & $\mathbf{1}$ & $\mathbf{2}$ & $\mathbf{3}$ & $\begin{array}{c}\text { Total } \\
\text { average }\end{array}$ \\
\hline Practices & 0.40 & 0.36 & 0.24 & 0.29 \\
\hline Raw materials & 0.60 & 0.39 & 0.35 & 0.40 \\
\hline Packaging & 0.52 & 0.36 & 0.31 & 0.35 \\
\hline Supply chain & 0.48 & 0.37 & 0.26 & 0.32 \\
\hline Transportation & 0.50 & 0.44 & 0.30 & 0.37 \\
\hline $\begin{array}{l}\text { Environmental Management Sys- } \\
\text { tem (EMS) }\end{array}$ & 0.33 & 1.00 & 0.00 & 0.34 \\
\hline Energy management & 0.61 & 0.43 & 0.28 & 0.37 \\
\hline Water management & 0.71 & 0.29 & 0.15 & 0.27 \\
\hline Waste management & 0.63 & 0.55 & 0.44 & 0.50 \\
\hline Air emission management & 0.71 & 0.24 & 0.11 & 0.23 \\
\hline Materials & 0.74 & 0.47 & 0.31 & 0.42 \\
\hline Culture & 0.52 & 0.34 & 0.17 & 0.27 \\
\hline Governance & 0.33 & 0.23 & 0.04 & 0.14 \\
\hline
\end{tabular}

Discriminant analysis confirmed results of the cluster analysis in verifying that all the companies were properly classified in their groups.

Cluster 1. Best practice. This group represents 42 companies (14\% of the sample), and is characterised by a high receptivity to environmental issues, that are expressed in the highest level of practice implementation in all the categories but EMS. The group has the largest average turnover and the highest vertical integration: $33 \%$ of the companies covers up to 4 production segments. The cluster is characterised by the 
highest level of environmental strategic proactivity $(2,33 / 3,00)$ and a medium level of cost savings $(0,39)$ and competitiveness $(0,30)$ perceived benefits.

Cluster 2. Good practice. This group contains 88 firms $(29 \%$ of the sample), that show a medium level of practice implementation. In average, companies included in this group have smaller dimension and a lower vertical integration compared to Group 1: $21 \%$ of the companies covers up to 3 production segments. The cluster is characterised by a high level of environmental strategic proactivity $(2,23 / 3,00)$ and a medium level of cost savings $(0,34)$ and competitiveness $(0,30)$ perceived benefits.

Cluster 3. Bad practice. This group represents $57 \%$ of the surveyed companies. These 173 firms expressed the lowest implementation of environmental management practices in all the categories. In average, companies included in this group have the lowest environmental proactivity $(1,89 / 3,00)$, the smallest dimension (in terms of turnover) and the lowest vertical integration: $16 \%$ of the companies covers up to 2 production segments. The companies perceive a low level of cost savings $(0,23)$ and competitiveness $(0,22)$ benefits.

\subsection{Environmental practice analysis and discussion}

Considering the average for all the companies, practices showing the highest level of implementation are: i) waste management, in particular waste reduction ( $48 \%$ of the sample) and separate waste collection $(89 \%)$; ii) use of process materials, in particular the use of certified materials $(60 \%)$; and iii) use of raw materials, that are sustainable $(64 \%)$ and certified (51\%). Practices presenting the worst implementation level are: i) Culture; ii) Air emission management; and iii) Governance.

Moving from Best to Bad practice, the implementation level decreases in all the categories but EMS. This last aspect represents a warning point for companies belonging to Cluster 1: despite such firms declare to implement a high number of environmental practices in all the areas, apparently they do not have a systematic management system in place. Overall, it can be stated that only a part of the Italian textile companies are fully concerned and committed about environmental issues and recognise the importance and necessity of incorporating environmental approaches into their management practices (Cluster 1). However, their similarities with Cluster 2 firms in terms of environmental strategic 
proactivity and perceived benefits poses a doubt about their leadership position: it is hard to imagine how a sustainability agenda with this many focus areas can break through and get the necessary buy-in to be successful. While there are several areas that companies need to comply with, it might be better to concentrate on a few themes and strategic priorities. To develop a clear set of priorities, it is important to start by analysing what matters most along the entire value chain, through internal analysis and consultations with stakeholders, including customers, regulators, and nongovernmental organizations. This process should enable companies to identify the sustainability issues with the greatest long-term potential and thus to create a systematic agenda. Once the priorities are identified, the next step is to develop a fact base from which to define the practices that need to be implemented. Companies have several management tools available, such as Environmental Performance Management Systems, supported by proper Environmental Management Information Systems and controlled through flexible governance structures. All these tools find a strong basis into a pervasive culture for environmental sustainability.

\section{Conclusion}

Environmental sustainability is gaining more and more relevance for textile companies since it can positively contribute to the firm's value creation process. Several companies are starting to pave the way towards sustainability through different management systems and approaches. The objective of this study was to identify and characterise groups of Italian textile companies that are statistically similar to each other considering the environmental management practices they adopt. This was carried out using a cluster analysis. Three types were identified: Best, Good and Bad practice. Moving from Best to Bad practice, average turnover and vertical integration decrease, as well as the implementation level of environmental management practices in all the categories (but EMS). The analysis showed that, although sustainability is somewhere on the corporate agenda, there are often problems with execution, even in the most committed companies, and the necessity to focus on a limited set of strategic priorities was highlighted. Finally, some directions for future research can be pointed out to expand this work: i) include in the sample textile companies from other countries; ii) enlarge the conceptual model to social sustainability aspects; and iii) 
test the relationship between the implementation of environmental management practices and companies' financial results.

\section{$6 \quad$ References}

1. Bonini, S., Bové, A.: Sustainability's strategic worth: McKinsey Global Survey results. McKinsey \& Company (2014).

2. Greeno, J. L.: Rethinking Corporate Environmental Management. Columbia J. World Bus. 27(3-4), 222-232 (1992).

3. Madsen, H., Ulhi, J.: Have Trends in Corporate Environmental Management Influenced Companies Competitiveness?. Green. Manag. Int. 44, 74-88 (2003).

4. Hubbard, G.: Strategic Management: Thinking, Analysis and Action. Prentice-Hall, Sydney (2000).

5. Chang, D., Kuo, L., Chen, Y.: Industrial changes in corporate sustainability performance-An empirical overview using data envelopment analysis. J. Clean. Prod. 56, 147-155 (2013).

6. European Commission: Sustainability of textiles. Issue Paper $\mathrm{n}^{\circ}$ 11. Retail Forum for Sustainability. Retrieved from: http://ec.europa.eu/environment/industry/retail/pdf/issue_paper_tex tiles.pdf (2013).

7. Smith, N.: Corporate Social Responsibility: Whether or How?. Calif. Manag. Rev. 45, 1-25 (2003).

8. Sroufe, R., Montabon, F., Narasimhan, R., Wang, X.: Environmental management practices. Green. Manag. Int. 40, 23-40 (2002).

9. Lucas, M. T.: Understanding environmental management practices: integrating views from strategic management and ecological economics. Bus. Strateg. Environ. 19(8), 543-556 (2010).

10. Colicchia, C., Marchet, G., Melacini, M., Perotti, S.: Building environmental sustainability: empirical evidence from Logistics Service Providers. J. Clean. Prod. 59, 197-209 (2013).

11. Resta, B., Dotti, S., Pinto, R., Bandinelli, R., Rinaldi, R., Ciarapica, F. E.: Practices for Environmental Sustainability in the Textile, Clothing and Leather Sectors: The Italian Case. Int. J. of Oper. Quant. Manag. 20(3), 193-225 (2014).

12. Wagner, M., Schaltegger, S.: The effect of corporate environmental strategy choice and environmental performance on competitiveness and economic performance: an empirical study of EU manufacturing. Eur. Manag. J. 22(5), 557-572 (2004). 